\title{
Analysis of Composition Design and Construction Technology in Graded Broken Stone Base of Bituminous Pavement
}

\author{
Huakui Yang \\ Jiangsu College of Engineering and Technology, Nantong Jiangsu, 226000, China
}

\begin{abstract}
Keywords: Bituminous pavement, Graded broken stone, Base, Composition design, Construction
\end{abstract} technology.

\begin{abstract}
The highway construction develops at top speed in our country. The monolithic architecture and building materials become better and approach perfection day by day. It also makes breakthrough in the technological process of graded broken stone base of bituminous pavement, to promote carrying capacity by interlocked-denseness impact and improve reflection crack in traditional structures to some degree, with very important promotional value. Starting from the development background of our bituminous pavement, it simply analyzes the composition design materials in graded broken stone base of bituminous pavement, concentrate on explaining its construction technology process and finally discuss problems in quality supervision so as to provide valuable reference and advice to construction units.
\end{abstract}

\section{Development Background of Bituminous Pavement in Our Country}

The traditional bituminous pavements mainly adopt semi-rigid base materials, with high use intensity, excellent rigidity and board property and good pavement bearing capacity. They are common in the structure of bituminous pavement base and cement concrete pavement base in our country. However, with the extension of service time, some problems occur, especially the technical matter of material itself. The half- rigid material would result in pavement cracking because of its own shrinkage character, and even pumping slurry under water impact, which is also one of the prime reasons that researchers hope to popularize other substitute technology. In recent years, pavement researchers intensify the study to flexibility characteristic of base structure, especially the application of graded broken stones.

Practical study finds that during the application of graded broken stones, their own intensity and the mixture base level in the modulus are not stable. It should intensify the study mechanism and matching analysis of materials before using them. Only intensifying the applicability of graded broken stone base materials of bituminous pavement could help to better apply this material into pavement surfacing. It should pay attention to the actual thickness of bituminous membrane, upgrade fundamental strength and structure stability of graded broken stones to decrease deformation caused by ambient pressure. What' s more, as to the graded broken stone base of bituminous pavement, the most important technology is to promote its stone intensity and material stability.

\section{Composition Design Material of Graded Broken Stone Base of Bituminous Pavement}

\section{Raw Material Requirement of Composition Design of Graded Broken Stone Base of Bituminous Pavement}

When studying the basic property of graded broken stone base materials of bituminous pavement, it should guarantee the broken stones intensity and stability meeting the actual demand. Specific parameters include: liquid limit under $25 \%$, plasticity index under $4 \%$, sand equivalent above $45 \%$, wear value under $35 \%$, crushing value under $26 \%$, stability test value under $12 \%$, needle and flake index under 20\%, etc. Establishing technical requirements is mainly for solving the problem that quality of graded broken stone base materials of bituminous pavement doesn't reach the standard. 
When using graded broken stone base of bituminous pavement, the biggest problem is the weathering of earth and shale, which would lead to not only pavement interlocked-denseness lacking the basic carrying capacity but also practical displacement structure appearing deviation. Only guaranteeing the standard material index can they promote ability to resist the plastic deformation from the outside world. In addition, it should use materials with low plasticity index, which could reduce structural destruction and meanwhile avoid instability and frozen sensibility caused by materials swelling in water. During the process of cardinal number control to graded broken stone base materials of bituminous pavement, it should also examine and weigh stability index to guarantee aggregate possessing favorable durability. Especially to the particles in cold region, it should guarantee their ability to resist freeze thawing so that it could truly increase durable years of graded broken stone base materials of bituminous pavement.

\section{Material Mix Proportion Requirement of Composition Design of Graded Broken Stone Base of Bituminous Pavement}

To the validation study of graded broken stone base materials of bituminous pavement, the most important is to control the mix proportion of materials. The actual strength and stability of graded aggregate is the key factor to influence its actual quality. Usually it would choose close-grained continuous grading to promote CBR value of integral materials and resisting permanent deformation ability. Specific parameters include nominal maximum particle size parameter, passing rate $(4.75 \mathrm{~mm}$ and $0.075 \mathrm{~mm})$, etc. ${ }^{[1]}$

Firstly, the nominal maximum particle size. During the process of matching and controlling materials, the nominal maximum particle size is in direct proportion to coarse aggregate number. If the value of nominal maximum particle size is big, then corresponding amount would be many. And the overall base structure would be easily to form stable basic framework and realize better CBR value. However, if the value of nominal maximum particle size is too big, it would cause separation and dispersion which would lead to the intensity and practical degree of density of whole graded broken stone base mixture of bituminous pavement giving a big discount. Therefore, after testing and considering the cost and basic usability, the nominal maximum particle size of broken stones should be controlled within $37.5 \mathrm{~mm}$ and above $26.5 \mathrm{~mm}$. At present, many cities would adopt $31.5 \mathrm{~mm}$ mixture with rather ideal resisting separation effect and actual strength.

Secondly, the passing rate. When studying the passing rate, the controlling parameters of particles less than $4.75 \mathrm{~mm}$ include dry density of aggregate, CBR numerical value parameter, triaxial shearing strength. And the specific numerical value and three parameters appear hump relation, with specific ratio control about 38\% which could guarantee the maximum of different indexes. In addition, under the condition of $0.075 \mathrm{~mm}$ particles increasing, the dry density, CBR numerical value and triaxial shearing strength of graded broken stone base aggregate of bituminous pavement would also incease. If the amount of $0.075 \mathrm{~mm}$ particles reaches to $5 \%$, the shearing strength could reach to the peak value. When the amount of $0.075 \mathrm{~mm}$ particles reaches to $6.8 \%$, the dry density and CBR numerical value could reach to the peak value [2]. However, if the $0.075 \mathrm{~mm}$ particles beyond effective range, it would result in frost heaving value rapidly increasing, even leading to serious water seepage problem.

\section{Analysis of Construction Technology of Graded Broken Stone Base of Bituminous Pavement}

\section{Mixture Blending Technological Process of Graded Broken Stone Base of Bituminous Pavement}

When mixing the mixture of graded broken stone base materials of bituminous pavement, foreigners usually adopt two patterns, road mix or plantmix. As for expressway, it usually adopts plantmix. In China, the plantmix is better since we have good condition and could further guarantee the cement stability. During the plantmix, it is easier to control the mixture grading structure, guaranteeing balanced configuration and meanwhile promoting its basic quality to ensure it with relevant standard. 
As for the mixture in graded broken stone base of bituminous pavement, water content is a rather important underlying parameter. However, it would be lost in transportation, pavement and rolling process, which need operators to control the specific operation and ensure water addition in mix with higher parameter than optimum water content. In addition, during the mix process, workers need to fully consider the around weather and operating environment. If the temperature is low, with high air humidity, water addition needs to be $0.5 \%$ to $1 \%$ higher than optimum water content. If the temperature is high, with dry air, water addition needs to be $1 \%$ to $2 \%$ higher than optimum water content. What's more, it should make use of effective measures to improve water-holding capacity of coarse aggregate. Some would water the coarse aggregate in advance to promote its hydroscopicity, ensure parameter meeting the actual demand of pavement.

\section{Mixture Pavement Technological Process of Graded Broken Stone Base of Bituminous Pavement}

When paving the mixture of graded broken stone base materials of bituminous pavement, foreigners would always adopt paver and land leveler to pave. In 1980s, our country mostly adopted land leveler to pave. Since the nominal maximum particle size of aggregate could be controlled in a smaller range, it gains good effect when paving the mixture of graded broken stone base of bituminous pavement. But as for the aggregate with big particle size, specific separation problem would occur. Thus with the improvement of technology, the common way to pave is paver in our country. During the practical operation process, since the actual thickness of graded broken stone layer is high, it would use two pavers to do drainage work to get more effective construction result. However, in some areas, they use land leveler which need to pay attention to its control technology to ensure flatness, elevation parameter, gradient, etc. meeting the standard to maximum avoid separation problem. When using land leveler, it needs to effectively control static pressure of road roller to ensure flatness meeting actual demand. And during operational process, there may be problems; especially the land leveler would generate layering up and down. That is to say, the new supplementary materials and the aggregate being compacted would be separated. Thus, the whole structure would become seriously dispersed. And due to number of occurrence, the basic aggregate would be broken. Thus, comparing to land leveler, paver is used more, with better thickness, flatness, etc. It is convenient for workers to control the data, promote quality of whole technological operation and ensure practical structure more balanced and effective ${ }^{[3]}$.

\section{Rolling Technological Process of Graded Broken Stone Base of Bituminous Pavement}

In order to promote integrity of whole operation, it needs to supervise and control the grinding process of graded broken stone base of bituminous pavement, especially promoting the structural strength of graded broken stone by grinding operation, to get the stone-to-stone structure of coarse particles and meanwhile guarantee complete connecting process of keying and fine aggregate. Thus, it needs to ensure the grinding operating mass to promote actual degree of compaction of graded broken stone base. The following two operations need to be concerned:

Firstly, it should optimize controlling of water content. The most basic condition is to guarantee the graded broken stone above optimum water content to realize optimization of compaction effect. It should control water content to realize stabilization of universe parameter structure. Constructors should guarantee timely grinding of graded broken stones. If the time is delayed, water would evaporate and aggregate become hard and dry. And the further grinding would not be so easy. Especially in summer, the water evaporates quickly. It should water them by atomizing watering cart to guarantee grinding work finishing smoothly. Also it needs to control the water. If the water content is high, it needs to immediately stop watering. After drying in the sun and water content meeting standard, it could start grinding ${ }^{[4]}$.

Secondly, it should optimize controlling to grinding thickness, which need constructors to choose the optimum rolling equipment and technological process. At present, many construction units adopt heavy third wheel road roller or vibratory roller to guarantee actual grinding thickness under $20 \mathrm{~cm}$. 
And the specific grinding technology should adopt vibratory roller and road roller together to do unite grinding. In addition, during practical grinding process, the main parameter control is according to weak vibration and strong vibration. The former is to serve compactness from the interlayer to surface layer. The latter is to serve compactness from the interlayer to bottom layer. It could effectively achieve rubbing and kneading of particles by plastic core-rubber-tires, to realize station keeping and meanwhile optimize grinding effect. And the whole materials grading proportion would be optimized. The concrete operations are static pressure to make sure about the compactness, alternating use of weak vibration and strong vibration to improve compactness of structure interior, and finally the overall grandly by plastic core-rubber-tires to realize thickness reset of the inlayer and surface. What needs attention is that the specific vibration time is up to the actual paving thickness and the compaction performance of graded broken stone base of bituminous pavement.

\section{Acceptance Management of Technological Construction Quality of Graded Broken Stone Base of Bituminous Pavement}

During the quality acceptance, supervisors should analyze and control the following parameters. The first is the grading of broken stones mixture, especially to the passing rate of $4.75 \mathrm{~mm}$ particles and $0.075 \mathrm{~mm}$ particles. The second is the basic quality of project aggregate, whose plasticity index and sand equivalent index parameter should be effectively controlled. The third one is the degree of compaction, mainly using sand cone method to do acceptance of materials ${ }^{[5]}$.

\section{Conclusion}

To sum up, during the analysis process of composition design and construction technology of graded broken stone base of bituminous pavement, constructors need to consider many-sided factors, guarantee highway construction project succeeding and meanwhile promote its real quality, realizing sustainable development of highway work.

\section{References}

[1] Liu Linan, Mix Design and Construction of Security Classification Bituminous Stabilized Macadam Base in Alpine Region. Private Science and Technology, 2013, 29(07):238-238.

[2] Ren Ruibo, Jiang Hongsheng, Wang Zhe, etc. Study to Stress State Change Rule of Metalling of Semi-rigid Bituminous Pavement with Macadam Base. Journal of Highway Communication Technology, 2015, 22(08): 12-14.

[3] Shi Guimei, Resisting Shear Performance of Graded Broken Stone Base of Mixed-type Bituminous Pavement. Journal of Building Materials, 2013, 14(04): 502-506,559.

[4] Hou Xiaoying, Li Lianxiu, Ke Yongchao, etc. Quality Control of ATB-25 Security Classification Bituminous Stabilized Macadam Base. Henan Science \& Technology, 2014, 41 (07): 41-42.

[5] Fu Junming, Kong Lingwei, Ke Changbo, etc. Behavioral Analysis of Bituminous Pavement Structural Mechanics with Bituminous Stabilized Macadam Drainage Base. Highway Engineering, 2014, 15 (05): 145-148. 